\title{
O QUE TEM DE VISUAL NA DANÇA E NA MÚSICA? RELATO DE EXPERIÊNCIA COM OS BOLSISTAS DO PIBID DE ARTES VISUAIS UNESC E OS ALUNOS DA E.M.E.I.E.F. OSWALDO HÜLSE
}

\author{
SILVA, Karlis Rejane Fernandes da; ${ }^{1}$ \\ MELLER, Sandréia de Farias ${ }^{2}$ \\ PEREIRA, Janete Piazzoli ${ }^{3}$ \\ PAVAN, Kariane ${ }^{4}$
}

\section{RELAÇÕES DE INTERDISCIPLINARIDADES NO ENSINO DA ARTE COM INTERFERÊNCIAS DO PROGRAMA PIBID}

Muitas são as respostas que se deram a pergunta sobre o que é arte, pois varia de acordo com o tempo, a cultura e até mesmo os conceitos de cada sujeito, sendo assim, segundo Freire:

Quando vivemos a autenticidade exigida pela prática de ensinar e aprender participamos de uma experiência total, diretiva, política, ideológica, gnosiológica, pedagógica, estética e ética, em que a boniteza deve achar-se de mãos dadas com a docência e com a seriedade. (FREIRE, 1996, p. 13).

A partir de conhecimentos construídos, é possível dizer de forma genérica, que arte é humana é uma área de conhecimento humano insubstituível na capacidade de proporcionar experiência única de reunir todas as dimensões humanas. No Brasil, foram importantes os movimentos entre a correlação arte e educação desde o século XIX, surge as mobilizações sociais com as práticas educativas, sociais, fisiológicas, pedagógicas, e o contexto da arte, também artística e estética, caracterizadas em diferentes movimentos históricos a compreender melhor na evolução educacional e sua relação com a própria vida.

É de extrema importância que cada sujeito entenda e conheça a arte, pois a mesma é essencial para a construção de nossa identidade e nos permite conhecer as manifestações de outras culturas, assim como resignificar nosso olhar diante das

\footnotetext{
1 SILVA, Karlis Rejane Fernandes da: Professora de arte na rede pública de Criciúma. karlisrfs@bol.com.br

${ }^{2}$ MELLER, Sandréia de Farias: Acadêmica do Curso de Artes Visuais - Licenciatura UNESC. sandreiafm@gmail.com

${ }^{3}$ PEREIRA, Janete Piazzoli: Acadêmica do Curso de Artes Visuais - Licenciatura UNESC

4 PAVAN, Kariane: Academica do Curso de Artes Visuais - Licenciatura UNESC. Karianepavan860@hotmail.com
} 
questões que estão postas na sociedade. A arte é um reflexo do ser humano e muitas vezes representa a sua condição social e essência de ser pensante. Neste sentido. Matos afirma:

[...] A arte possui um tônus revolucionário especial: não pode mudar a sociedade, mas é capaz de transformar a consciência daqueles que modificam o mundo. Isso porque indica um 'princípio de realidade incompatível com a coerção política e psíquica (MATOS, 1993, p. 110).

Desde as manifestações artísticas da antiguidade, já se percebia sinais distintos de cada cultura. A História da arte é a história de qualquer atividade ou produto realizado pelo Homem com propósito estético ou comunicativo, enquanto expressão de idéias, emoções ou formas de ver o mundo sinais e características que mais tarde identificaríamos como expressões de diferentes culturas, revelando as várias identidades culturais.

Mesmo em diferentes contextos históricos e culturais a arte sempre representou e localizou o sujeito apreciador, ou mesmo artista de como as diferentes expressões, os estilos, pensamentos, e manifestações singulares. É possível dizer então, que "arte são certas manifestações da atividade humana, diante das quais nosso sentimento é admirativo, isto é, nossa cultura possui uma noção que denomina solidamente algumas de suas atividades e as privilegia" (COLI, 1987, p. 08).

A Arte é importante no trabalho educativo, pois procura, através das tendências individuais, encaminhar a formação do gosto, estimular a inteligência e contribui para a formação da personalidade do sujeito sem ter como preocupação única e mais importante a formação de artistas. Segundo Ana Mae Barbosa, uma das maiores pesquisadoras brasileiras sobre o tema arte- educação, em seu livro Inquietações e Mudanças no Ensino da Arte, o potencial da arte como área de conhecimento significa:

Por meio da Arte é possível desenvolver a percepção e a imaginação, apreender a realidade do meio, desenvolver a capacidade crítica, permitindo ao indivíduo analisar a realidade percebida e desenvolver a criatividade de maneira a mudar a realidade que foi analisada" (BARBOSA, 2003, p.18)

Sendo assim, é importante que os professores aperfeiçoem suas práticas pedagógicas e que, o ensino e a aprendizagem de arte ocorram da maneira 
adequada. A Arte oportuna um modo novo de compreender 0 mundo contemporâneo, de com ele se relacionar e nele se inserir, que ela estabelece uma nova ordem no contato com o mundo cultural, um novo olhar que pode resignificar conceitos e práticas.

No empenho a mobilização em obter avanços no ensino e na aprendizagem de Arte nas escolas. Uma conquista importante ocorreu com a Lei de Diretrizes e Bases da Educação Nacional (n. 9.394, de 20 de dezembro de 1996), que estabeleceu:

O ensino de Arte constituirá componente curricular obrigatório, nos diversos níveis da educação básica, de forma a promover o desenvolvimento cultural dos alunos. (Art. 26, §2º)

Caminhar para que a área de Arte seja trabalhada como área de conhecimento, com conteúdo próprio aos alunos, pela sua relevância no acesso aos bens culturais e na participação dos alunos na sociedade, por intermédio da arte. Portanto, ao se refletir sobre o processo educativo, observa-se que as questões sociais da atualidade tratadas pelos temas transversais têm na Arte um campo privilegiado para seu desenvolvimento.

Experimentar e explorar as possibilidades de cada linguagem artística. É importante que o aluno, além de produzir e se desenvolver nas linguagens artísticas que já fazem parte da sua experiência de vida, entre em contato, experimente, explore e se desenvolva no aprofundamento de cada linguagem, que deverá ser considerada em sua extensão, ampliando seu repertório expressivo e sua capacidade de compreensão do mundo.

Compreender e utilizar a arte como linguagem, é encontrar vertentes para a expressão e comunicação para ideias, sentimentos e vivências, desenvolvendo imaginação, percepção, pesquisa pessoal e/ou grupal, contribui no desenvolvimento afetivo, cognitivo, estético e artístico, sendo, que a escola oportuniza esse tipo de conhecimento de fazer leituras da realidade e de conhecer possibilidades diferenciadas de significá-la de identificar, relacionar e compreender a arte como fato histórico contextualizado nas diversas culturas, conhecendo, respeitando e podendo observar as produções presentes no entorno, assim como as demais do patrimônio 
cultural e do universo cultural e natural, identificando a existência de diferenças nos padrões artísticos e estéticos de diferentes grupos.

[...] Arte é um sistema de manifestações e códigos que se interpenetram e se recodificam a cada momento; uma forma particular de ver e expressar o mundo, que atua como uma reação emocional e conceitual a vida. A linguagem artística busca resolver um problema artístico no qual se encontra o artista, possibilitando-se o pensamento e a expressão de si e de sua época por imagens - sonoras, visuais, corporais, poéticas...O que vigora hoje na arte não é apenas o conhecimento sensível ou mesmo a beleza é a inteireza, a significação. É um campo privilegiado da educação estética. (GARCIA, 2000, p.22- 23).

Á uma reflexão sobre o desenvolvimento, e a aprendizagem, diante de pesquisadores, entre tantos, possibilita novos conhecimentos aos alunos outras linguagens artísticas, ao ensino da arte. Entende-se então, que o professor é aquele que transforma sua pratica e os resultados para uma reflexão, acreditando que a verdadeira aprendizagem acontece quando o sujeito testa suas hipóteses sobre o mundo, sobre a vida, e a sociedade, pois aprender na escola e como se aprender na vida; buscar soluções para suas inquietações.

A partir do fortalecimento da importância ao aprendizado da arte passa ser uma disciplina obrigatória no currículo escolar, de acordo com a LDB oㅜ 9.394/96, e tem função tão importante quanto as outras áreas. A disciplina de arte proporciona ao aluno, o fazer artístico, apreciação e fruição artística, desenvolvendo a percepção a reflexão e a imaginação, segundo a proposta dos Parâmetros Curriculares Nacionais, "A Arte tem uma função tão importante quanto à dos outros conhecimentos no processo de ensino e aprendizagem. A área de Arte está relacionada com as demais áreas e tem suas especificidades". É necessário que o aluno ao longo de sua escolaridade, tenha oportunidade de vivenciar inúmeras formas de arte; de modo que cada modalidade possa ser desenvolvida e apreciada.

$O$ aprendizado a arte estimula $O$ contato com diferentes linguagens artísticas, é importante, pois através dela que os alunos se tornam capazes de se expressar criticamente, relacionando seu cotidiano com as questões de ensino aprendizagem. Ensinar arte é buscar trabalhar com questões históricas da arte, mas também envolver o cotidiano do aluno, garantindo liberdade para construção do percurso próprio de criação. Segundo os Parâmetros Curriculares Nacionais (BRASIL, 1997, p. 35): 
Aprender arte é desenvolver progressivamente um percurso de criação pessoal cultivado, ou seja, alimentado pelas interações significativas que 0 aluno realiza com aqueles que trazem informações pertinentes para o processo de aprendizagem (outros alunos, professores, artistas, especialistas), com fontes de informação (obras, trabalhos dos colegas, acervos, reproduções, mostras, apresentações) e com o seu próprio percurso de criador.

Para aprender arte e preciso desenvolver progressivamente um percurso pessoal de criação, mas também ampliação de repertório e informações, sendo necessário que o aluno faça arte, entre as linguagens artísticas. Entende-se:

\begin{abstract}
Ensinar arte em consonância com os modos de aprendizagem do aluno, significa, então, não isolar a escola da informação sobre a produção histórica e social da arte e, ao mesmo tempo, garantir ao aluno a liberdade de imaginar e edificar propostas artísticas pessoais ou grupais com base em intenções próprias. (BRASIL, 1997, p. 35)
\end{abstract}

Então, que o professor é aquele que transforma sua pratica e os resultados para uma reflexão, acreditando que a verdadeira aprendizagem acontece quando o sujeito desafia suas hipóteses sobre o mundo, sobre a vida, e a sociedade, pois aprender na escola e como se aprender na vida; buscar soluções para suas inquietações. De encontro ao ensino de Arte o MEC lança a Proposta de Diretrizes para a Formação Inicial de Professores da Educação Básica em Cursos de Nível Superior, que no tocante a formação do professor de arte refere que:

Há ainda a necessidade de se discutir a formação de professores para algumas áreas de conhecimento desenvolvidas no ensino fundamental, como Ciências Naturais ou Artes, que pressupõem uma abordagem equilibrada e articulada de diferentes disciplinas (Biologia, Física, Química, Astronomia, Geologia, etc, no caso de Ciências Naturais) e diferentes linguagens (Música, Dança, das Artes Visuais, Teatro, no caso de Arte), que, atualmente, são ministradas por professores preparados para ensinar apenas uma dessas disciplinas ou linguagens. (BRASIL, 1997, p. 34).

Pensar professor como um processo de construção permanente é apenas um começo para refletirmos sobre quais implicações o ensino de arte nos aponta na contemporaneidade. "Um professor valorizado, respeitado e habilitado pode criar uma escola que atrai os alunos, uma escola inclusiva, na qual o aluno quer aprender e aprender a participar" (IAVELBERG, 2003, p. 63). 
Entende-se que o professor precisa suporte para que isso aconteça, pois somente dessa forma o aluno passará a pensar a arte como o modo de criação, reflexão, recurso, conhecimento e, principalmente, como fonte de aprendizado se tornando capaz de estabelecer relações entre a arte e outras formas de saber.

\section{APRENDIZADO NAS EXPERIÊNCIAS COM AS DIFERENTES LINGUAGENS ARTÍSTICAS}

Com as experiências vivenciadas junto aos alunos e a professora, entre espaço, e tempo ao conhecimentos, metodológicos entra em cenário o olhar para o objeto concreto, a onde a instituição escolar oportuna o indivíduo as inúmeras vivencias em forma de arte; de modo que cada modalidade possa ser desenvolvida, e apreciada, a professora com o objetivo de despertar, o fluir ao conhecimento, possibilita aos alunos no espaço escolar, explorando com instrumentos musicais como, o berimbau, a cuba, e o tamborim para ampliar seus saberes, aprendizado sobre instrumentos de percussão, a percepção, e o repertório dos gêneros que conheciam.

Vendo a evolução de todo o trabalho em vários contextos, o movimento do corpo também vem surgindo através da dança" capoeira" é uma expressão cultural Brasileira que mistura arte marcial, esporte, cultura popular e música. Desenvolvida no Brasil, principalmente por descendentes de escravos Curriculares Nacionais (BRASIL, 1997, p. 72).

É importante, portanto, que o corpo não seja tratado como "instrumento" ou "veículo" a dança, como comumente se pensa. O corpo é conhecimento, emoção, comunicação, expressão. Ou seja, o corpo somos nós e nós somos o nosso corpo. Portanto, o corpo é a nossa dança e a dança é o nosso corpo.

Com base nesse aspecto a dança é possível conhecer diferentes culturas, além de possibilitar o trabalho com a corporeidade dos alunos. Afirma então "Como isso, poderão estabelecer relações corporais críticas e construtivas com diferentes maneiras de ver/sentir o corpo em movimento e por tanto, com diferentes épocas e culturas". O papel professor é importante para que os alunos aprendam a 
desenvolver o fazer artístico com prazer e criatividade, para que possam gostar de fazer arte ao longo da trajetória (BRASIL, 1997. p.74)

Dessa forma, a escola pode desempenhar papel importante na educação do corpo e do processo interpretativo e criativo de dança, pois dará aos alunos subsídios para melhor compreender, desvelar, desconstruir, revelar e, se for o caso, transformar as relações. Quem dança tem mais facilidade para construir a imagem do próprio corpo, o que é fundamental para o crescimento e a maturidade do indivíduo e a formação de sua consciência social.

\section{A INTERDISCIPLINARIDADE NO ENSINO DA ARTE COMO FONTE DE ENRIQUECIMENTO NA FORMAÇÃO INTEGRAL DO SUJEITO}

A arte sempre esteve presente na história. Tanto que foi a primeira forma de expressão encontrada pelo homem para sua comunicação. Podemos observar isso nas pinturas rupestres encontradas nas cavernas. $E$ não se limitando somente a pinturas, também realizaram esculturas em diferentes materiais. E com o decorrer dos anos, e com o desenvolvimento intelectual a arte passou a abranger outras vertentes, como a música, a literatura, dança e teatro. E independente de qual linguagem artística, todas as pessoas são naturalmente seres inclinados para a arte, já que ela é necessária inclusive para nossa comunicação, e através dela temos a possibilidade de expressar emoções, pensamentos, sentimentos e podemos imaginar e criar, dando-lhes vida independente da idade.

Por isso em nossas aulas com a presença do PIBID, buscamos proporcionar para o aluno o maior nível de interação com a arte, sempre fazendo ligações entre as aulas e as diversas vertentes da arte. Pois entendemos que a arte deve ser trabalhada como um todo para que o aluno possa compreender e interagir principalmente a arte contemporânea.

Em uma das nossas experiências com o PIBID, trabalhando a cultura afro-brasileira, introduzimos a música em nossa aula. E para isso, selecionamos diversas músicas de diferentes estilos musicais, e também algumas imagens de diversos artistas e movimentos artísticos. Pedimos para os alunos relacionarem as músicas com as imagens e falarem um pouco sobre esta relação. E o resultado foi surpreendente. Relacionavam as batidas da música com a forma da pincelada das pinturas e o ritmo com as cores e com os movimentos criados pelas formas. 
Em outra experiência, sequencial de trabalho, levamos para os alunos diversos instrumentos da cultura afro-brasileira, como o berimbau, atabaque e o pandeiro. Os alunos além de aprenderem a história e estrutura dos instrumentos, tiveram um momento de experimentação e foram ensinados como manuseá-los emitindo sonoridade rítmica neles. Em seguida iniciamos uma música em conjunto e os alunos expressaram a vontade de dançar capoeira, e iniciaram o visual, como quais vestimentas devem ser usadas e as cores que o ritmo remete. A pedido dos alunos, iniciamos uma batalha de rimas, modalidade utilizada na cultura hip hop, mas com algumas regras. Deveriam ser utilizados os ritmos afro brasileiro e o nome dos instrumentos musicais estudados estando estes nas rimas.

Os alunos estariam improvisando, mas com direção. Pois o a arte, e todas as suas vertentes, não pode ser limitada apenas no ouvir ou ver, como algo impraticável, mas deve ser praticada tendo como foco a experiência trazida pela vivencia do aluno através das aulas de artes. Pois através da arte o aluno se torna um ser pensante, além do que a ciência pode proporcionar. Pois a arte faz liberar no aluno a imaginação, algo que por sua vez, podemos dizer que tem virado um artigo de luxo. Ela é capaz de proporcionar um elevado nível de imaginação no aluno. Levando o mesmo á curiosidade, gerando conhecimento e realização. E se for trabalhada em interdisciplinaridade, podermos enfim considerar e escola, uma fábrica de gênios. Pessoas com mais flexibilidade, diferentes habilidades, e rapidez de raciocínio, que nem a própria lógica, sozinha, poderia alcançar.

\begin{abstract}
Um aluno que tenha se acostumado a criar em diferentes linguagens, mesmo sem ser a linguagem que ele mais domina, vai estar mais bem preparado para enfrentar os embates cotidianos da vida e de seu trabalho, assim como se sentirá apto a estar buscando novas saídas para qualquer problema. (VASCONCELLOS, 2006. p. 12).
\end{abstract}

De acordo com a autora, se o aluno tiver maior contato com a criação, ele não se abalará diante das circunstancias, pois estará mais preparado para a vida. Pois além de ter um elevado nível de conhecimento estará acostumado a colocar suas ideias e imaginação em pratica, fazendo de si uma pessoa mais ousada, segura e um profissional completo.

Pois a arte, nos dias de hoje, desenvolve no aluno diferentes conhecimentos, incluindo a mais avançada tecnologia, já que a arte não é mais 
apenas tinta e tela, temos também a pintura digital, curtas, músicas entre outros, que envolvem a tecnologia atual, fazendo com que o mesmo também tenha mais desenvoltura na coordenação motora. Fazendo com que o mesmo se torne um ser crítico, que não aceita apenas as verdades impostas, mas o proporciona a capacidade e o estimulo necessário para que o mesmo a encontre. $E$ através de nossas aulas no Oswaldo Hülse, buscamos instigar o aluno a manifestar a participação com sua reflexão a respeito do tema o fazer artístico.

Não deveríamos estar deixando fluir a "imaginação" de nossos alunos e alunas, e a sua "intuição" e sua "sensibilidade", e ao pretender educar, educar (o que não significa domesticar) o olho, o ouvido, o tato, o olfato e a mesma gustação, formas de conhecimento do mundo e de si mesmo, pois só assim Ihes será oferecida a possibilidade de diversidade de pensamento, de diversidade de linguagens? Musicalizar a vida, poetizar a vida, sentir o cheiro da vida, cantar e dançar a vida, ver a beleza da vida, tornar a vida bela. (GARCIA, 2000. p. 34).

Como a autora ressaltou, a arte leva o aluno a "viajar" com sua imaginação, usando seus sentidos, e ativando sua sensibilidade. E através da arte a vida fica mais bela, diversificada, movimentada. Mesmo que a produção artística seja carente em beleza, ela tem o poder de passar reações, sentimentos, os quais mexem com nossos sentidos, com nossa visão de vida. "Por meio dela, a imaginação humana poderia se tornar concreta. [...] A arte expressa o sentir, concretizando os sentimentos de uma forma que possam ser percebidos" (VASCONCELLOS, 2006. p. 41). Em uma de nossas aulas, levamos para os alunos alguns artistas contemporâneos de diferentes linguagens, para que os alunos vissem a arte como algo atual e possível a eles. Apresentamos o desenhista e cineasta contemporâneo Tim Burton e os alunos amaram. E perceberam que a arte é muito mais presente em nossa vida do que percebemos, e que a arte pode ser estática como uma pintura ou dinâmica como uma peça de teatro. Então pedimos para os alunos criarem um personagem, tendo a forma desejada do aluno. $E$ o resultado foi incrível. Vimos trabalhos autênticos e criativos pois além de criarem a forma do personagem, alguns criaram nome e outros foram mais longe, criando também uma história.

Logo a arte não pode ser definida por conceito apenas. Pois assim como pode ser considerada a ciência da expressão em suas diversas vertentes, ela tem 
um poder de expressar sentimentos e pensamentos através de diferentes formas seja estática ou dinâmica. Afinal a arte é uma linguagem universal que ultrapassa gerações e modifica pensamentos. E em nossas experiências no PIBID confirmamos que através da interdisciplinaridade alcançamos enriquecimento na formação de nossos alunos. A arte faz com que possamos aprender descobrindo um novo mundo. Faz nossa imaginação ser real, e nossa identidade concreta.

\section{CONCLUSÃO}

As relações de interdisciplinaridades no ensino da arte na Escola Oswaldo Hülse foram conquistadas ao longo do processo de aprendizagem dos alunos com notáveis interferências do programa PIBID por meio dos futuros professores, funcionando até mesmo, como formação continuada tendo em vista as contribuições que este nos traz.

Em nossos momentos de estudos no PIBID de Artes Visuais, como acadêmicas, concluímos que, o PIBID é transformador na vida dos acadêmicos em sua formação. Ele também ajuda nas escolas no aprendizado dos estudantes com mudanças no aprendizado do ensino de Artes, e na construção de cidadãos para um futuro melhor, em sua cultura e cidadania. Ele ajuda pessoas a recuperar emoções e lembranças de seu passado, dando mais vida e a essas pessoas com amor e compromisso de formar professores de qualidade para estar preparado o para mercado de trabalho.

\section{REFERÊNCIAS}

BARBOSA, Ana Mãe (Org.). Inquietações e mudanças no ensino da arte. 2.ed. São Paulo: Cortez, 2003.

BRASIL, Secretaria da Educação Fundamental. Parâmetros Curriculares Nacionais: Arte. - Brasília: MEC/SEF, 1997

COLI, J. O que é arte. São Paulo: Brasiliense Primeiros Passos, 1987.

FREIRE, P. 1996. Pedagogia da autonomia: saberes necessários a prática educativa. 25.ed, - são Paulo: Paz e Terra, p. 13. 
GARCIA, Regina Leite. Múltiplas linguagens na vida - por que não múltiplas linguagens na escola p.12 In Garcia, Regina Leite. Múltiplas linguagens na Escola. Rio de Janeiro. Ed DP\&A. 2000

IAVELBERG, Rosa. Para gostar de aprender arte: sala de aula e formação de professores. Porto Alegre: Artmed, 2003.

MATOS, Olgaria C. F. O Luminoso Visionário: Benjamim. Leitor de Descartes e Kant. São Paulo: Brasiliense, 1993.

VASCONCELLOS, Marcya. A arte entra em cena na escola. In Silva, Ângela Carrancho. Escola com arte: multicaminhos para a transformação. Porto Alegre. Ed. Mediação, 2006. 